Jurnal ECOTIPE, Vol. 7, No.2, Oktober 2020, Hal. 108-116

p-ISSN 2355-5068, e-ISSN 2622-4852

Akreditasi Kemenristekdikti (SINTA 4), SK. No.10/E/KPT/2019

DOI: 10.33019/jurnalecotipe.v7i2.1883

\title{
Desain dan Implementasi Bidirectional DC-DC Converter Untuk Penerangan Darurat
}

\author{
Nancy Rahayu ${ }^{1}$, Irianto ${ }^{2}$, Eka Prasetyono ${ }^{3}$ \\ Program Studi Teknik Elektro Industri, Departemen Teknik Elektro, Politeknik Elektronika Negeri Surabaya ${ }^{1}$ \\ Program Studi Teknik Elektro Industri, Departemen Teknik Elektro, Politeknik Elektronika Negeri Surabaya ${ }^{2}$ \\ Program Studi Teknik Elektro Industri, Departemen Teknik Elektro, Politeknik Elektronika Negeri Surabaya ${ }^{3}$ \\ *nancyrahayu9@gmail.com¹, irianto@pens.ac.id², eka@pens.ac.id ${ }^{3}$
}

\begin{abstract}
The lighting system is one of the biggest uses of electrical energy. Currently, lighting systems, especially emergency lighting, are urgently needed to deal with sudden blackouts at night. The emergency lighting gets a source of electrical energy from the battery and the battery gets a source of electrical energy from PLN. To regulate the source of electrical energy, a DC-DC converter with a bidirectional method is used. The bidirectional converter is a converter that has 2 functions, namely buck mode and boost mode which works when the main source of PLN goes out, automatically the lighting system will be supplied by the battery as a backup source. The buck mode in the charging process is used to store electrical energy into a battery with a battery capacity of $12 \mathrm{~V} \mathrm{30Ah}$. While the boost mode in the discharging process is used to distribute electrical energy from the battery to the load with a lamp load of $10 \mathrm{~W}$. The charging and discharging processes are controlled using proportional integral control analytic methods. The charging process in buck mode with a $K_{p}$ value of 8.62 and $K_{i}$ of 17240 , the output voltage value is $13.99 \mathrm{~V}$. While the discharging process in boost mode with a $K_{p}$ value of 2.44 and $K_{i}$ of 344.63 , the output voltage value is $23.99 \mathrm{~V}$.
\end{abstract}

Keywords : Bidirectional DC-DC Converter, Charging and Discharging Battery, Emergency Lamp, PI Controller.

\section{INTISARI}

Sistem penerangan merupakan salah satu pemakaian energi listrik yang besar. Saat ini sistem penerangan terutama penerangan darurat sangat dibutuhkan untuk mengatasi kondisi tiba-tiba padam pada malam hari. Penerangan darurat tersebut mendapatkan sumber energi listrik dari baterai dan baterai mendapatkan sumber energi listrik dari PLN. Untuk mengatur sumber energi listrik tersebut maka digunakan suatu konverter DC-DC dengan metode bidirectional. Bidirectional converter merupakan 1 konverter yang mempunyai 2 fungsi yaitu mode buck dan mode boost yang bekerja ketika sumber utama dari PLN padam maka secara otomatis sistem penerangan akan di suplai oleh baterai sebagai sumber cadangan. Mode buck dalam proses charging digunakan untuk menyimpan energi listrik ke dalam baterai dengan kapasitas baterai sebesar 12V 30Ah. Sedangkan mode boost dalam proses discharging digunakan untuk menyalurkan energi listrik dari baterai ke beban dengan beban lampu sebesar 10W. Proses charging dan discharging dikontrol menggunakan kontrol proportional integral metode analitik. Proses charging pada mode buck dengan nilai $\mathrm{K}_{\mathrm{p}}$ sebesar 8,62 dan $\mathrm{K}_{\mathrm{i}}$ sebesar 17240 didapatkan nilai tegangan keluaran sebesar 13,99V. Sedangkan proses discharging pada mode boost dengan nilai $\mathrm{K}_{\mathrm{p}}$ sebesar 2,44 dan $\mathrm{K}_{\mathrm{i}}$ sebesar 344,63 didapatkan nilai tegangan keluaran sebesar $23,99 \mathrm{~V}$.

Kata kunci: Bidirectional DC-DC Converter, Charging dan Discharging Baterai, Kontrol PI, Lampu Darurat.

\section{PENDAHULUAN}

Energi memiliki peranan penting dalam keberlangsungan kehidupan manusia hingga saat ini. Salah satu energi yang dibutuhkan adalah energi listrik pada sistem penerangan. Sistem penerangan merupakan salah satu pemakaian energi listrik yang besar. Saat ini sistem penerangan terutama penerangan darurat sangat dibutuhkan oleh masyarakat untuk mengatasi kondisi listrik yang tiba-tiba padam pada malam hari. Sehingga penerangan darurat sangat diperhitungkan keberadaannya di masyarakat. 
Jurnal ECOTIPE, Vol. 7, No.2, Oktober 2020, Hal. 108-116

p-ISSN 2355-5068, e-ISSN 2622-4852

Akreditasi Kemenristekdikti (SINTA 4), SK. No.10/E/KPT/2019

DOI: 10.33019/jurnalecotipe.v7i2.1883

Penerangan darurat menggunakan sumber listrik yang berasal dari baterai dan di dalamnya terdapat switch otomatis untuk mengubah catu daya listrik utama (PLN) ke listrik cadangan. Tetapi listrik cadangan memiliki kemampuan terbatas dalam menyuplai lampu sedangkan ketika terjadi mati lampu, tidak dapat diprediksi sumber listrik utama dapat hidup kembali. Secara umum sumber listrik lampu darurat yang berasal dari baterai memiliki kemampuan dalam menyalakan sistem sekitar $4-6$ jam saja. Tetapi pada peraturan maksimal PLN diperbolehkan melakukan pemadaman adalah 5 jam, namun bisa saja terjadi kendala yang menyebabkan pemadaman yang lebih dari itu.

Kenyataannya, tegangan DC dari sumber (PLN) atau penyimpanan energi (baterai) tidak sesuai dengan spesifikasi tegangan beban yang diinginkan sehingga dibutuhkan konverter DC-DC menggunakan metode bidirectional yang berfungsi untuk proses pengisian baterai dan proses menyalurkan energi listrik ke beban sehingga terdapat dua fungsi pada satu konverter.

Pada saat sumber utama (PLN) menyala, arus mengalir menuju baterai sehingga baterai mengalami proses charging dengan menurunkan tegangan (mode buck) dan ketika sumber utama (PLN) padam maka beban lampu akan menyala yang mendapat suplai dari baterai dengan menaikkan tegangan (mode boost). Simulasi dilakukan menggunakan software PSIM. Proses switching bidirectional DC-DC converter dilakukan secara otomatis dimana konfigurasi disesuaikan yaitu sebagai pembangkit sinyal Pulse Width Modulation (PWM).

\section{LANDASAN TEORI}

\section{A. Buck Converter}

Buck converter adalah konverter yang bekerja sebagai step down DC(Direct Current) dengan tegangan output lebih rendah dari tegangan $\left(V_{o}<V_{S}\right)$. Prinsip kerjanya adalah menurunkan tegangan DC dengan mengatur besar duty cycle switching. Rangkaian Buck converter pada gambar 1 terdiri dari tegangan input $\left(V_{S}\right)$, saklar aktif (MOSFET), dioda, induktor, kapasitor, dan resistor. Switch pada buck converter akan bekerja terus-menerus. Kecepatan switch (dalam realisasinya) akan bergantung pada duty cycle yang digunakan.

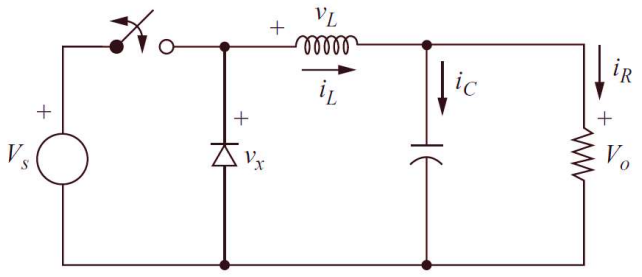

Gambar 1. Rangkaian buck converter

Pinsip kerja pada buck converter memiliki 2 kondisi yaitu pada saat saklar dalam kondisi "ON" seperti pada Gambar 2.

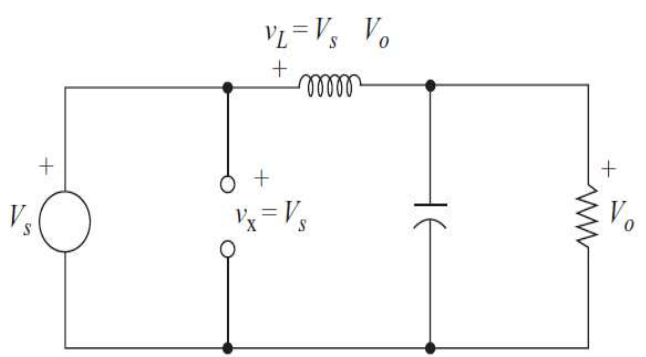

Gambar 2. Rangkaian buck converter saklar "ON"

Ketika dalam kondisi saklar "ON" dioda bekerja reversed/block sehingga suplai input mengalir ke induktor juga ke beban. Rumus matematiknya sebagai berikut:

$V_{L}=V_{S}-V_{o}$

$V_{L}(t)=L \frac{d i}{d t}$

$L \frac{d i}{d t}=V_{s}-V_{o}$

$V_{S}=L \frac{\Delta i_{L}(o n)}{D T}+V_{o}$

$\Delta_{i_{L(\text { closed })}}=\frac{\left(V_{S}-V_{o}\right) D T}{L}$

Pada kondisi 2 yaitu saat saklar dalam kondisi "OFF" dapat dilihat pada Gambar 3.

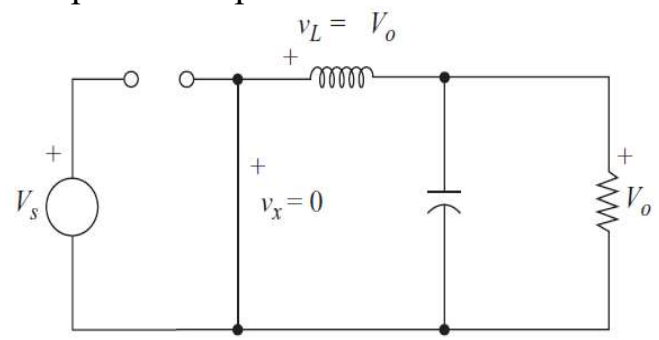

Gambar 3. Rangkaian buck converter saklar "OFF"

Ketika saklar dalam kondisi "OFF" dioda bekerja forward/unblock sehingga energi yang disimpan di 
Jurnal ECOTIPE, Vol. 7, No.2, Oktober 2020, Hal. 108-116

p-ISSN 2355-5068, e-ISSN 2622-4852

Akreditasi Kemenristekdikti (SINTA 4), SK. No.10/E/KPT/2019

DOI: 10.33019/jurnalecotipe.v7i2.1883

induktor dapat mengalir ke beban. Rumus matematiknya sebagai berikut.

$V_{L}=-V_{o}$

$V_{L}(t)=L \frac{d i}{d t}$

$-V_{o}=L \frac{\Delta i_{L_{(o f f)}}}{\tau_{o f f}}$

$-V_{o}=L \frac{\Delta i_{L_{(o f f)}}}{(1-D) T}$

$\Delta i_{L_{(o f f)}}=-\frac{V_{o}(1-D) T}{L}$

\section{B. Boost Converter}

Boost Converter adalah step up konverter atau konverter DC-DC dengan tegangan output yang lebih besar dari tegangan input $\left(V_{o}>V_{s}\right)$. Prinsip kerjanya adalah menaikkan tegangan DC dengan mengatur besar duty cycle switching. Rangkaian Boost converter pada gambar 4 terdiri dari tegangan input $\left(V_{s}\right)$, saklar aktif (MOSFET), dioda, induktor, kapasitor, dan resistor.

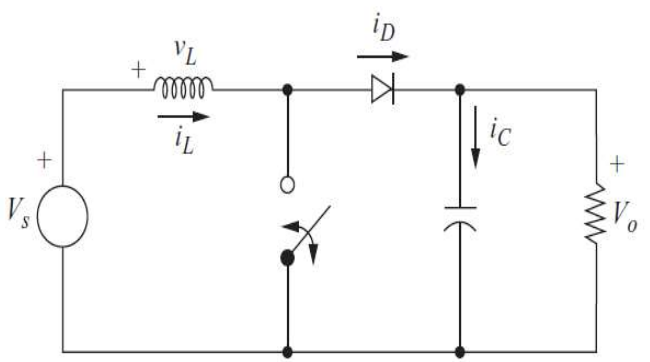

Gambar 4. Rangkaian boost converter

Pinsip kerja pada boost converter memiliki 2 kondisi yaitu pada saat saklar dalam kondisi "ON" seperti pada Gambar 5.

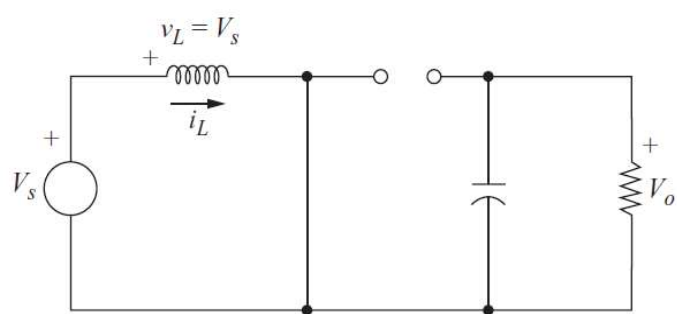

Gambar 5. Rangkaian boost converter saklar "ON"

Ketika saklar dalam kondisi "ON" dioda bekerja reversed, sehingga output open/terisolasi. dan inputan menyuplai energi ke induktor. Rumus matematiknya sebagai berikut :

$V_{L}=V_{S}$

$V_{L}(t)=L \frac{d i}{d t}$
$V_{s}=L \frac{\Delta i_{L_{(o n)}}}{\tau_{o n}}$

$V_{S}=L \frac{\Delta i_{L_{(o n)}}}{D T}$

$\Delta i_{L_{(o n)}}=\frac{V_{S} D T}{L}$

Pada kondisi 2 yaitu saat saklar dalam kondisi "OFF" dapat dilihat pada Gambar 6.

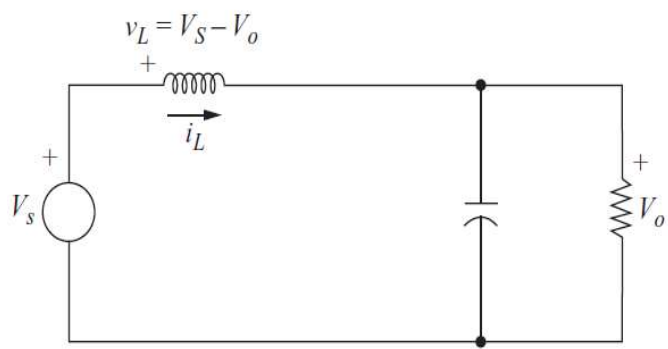

Gambar 6. Rangkaian boost converter saklar "OFF"

Ketika saklar dalam kondisi "OFF" output menerima energi dari input dan induktor sehingga outputnya lebih besar daripada inputan. Rumus matematiknya sebagai berikut.

$V_{L}=V_{S}-V_{o}$

$V_{L}(t)=L \frac{d i}{d t}$

$V_{s}=L \frac{\Delta i_{L_{(o f f)}}}{\tau_{o f f}}+V_{o}$

$V_{S}=L \frac{\Delta i_{L_{(o f f)}}}{(1-D) T}+V_{o}$

$\Delta i_{L_{(o f f)}}=\frac{\left(V_{S}-V_{o}\right)(1-D) T}{L}$

\section{Bidirectional DC-DC Converter}

Bidirectional converter merupakan konverter yang dapat mengalirkan daya ke kedua arah yang berbeda. Aliran arus pada bidirectional converter harus bisa membawa arus pada kedua arah yang berlawanan melalui switch converter. Dengan menggunakan sistem bidirectional dapat mengurangi biaya, meningkatkan efisiensi dan performa pada rangkaian. Bidirectional converter biasanya diaplikasikan dengan menggunakan switch daya seperti MOSFET dan IGBT. Dioda yang terpasang seri dengan saklar akan digunakan untuk mengalirkan arus dua arah. Rangkaian bidirectional converter dapat dilihat pada Gambar 7. 


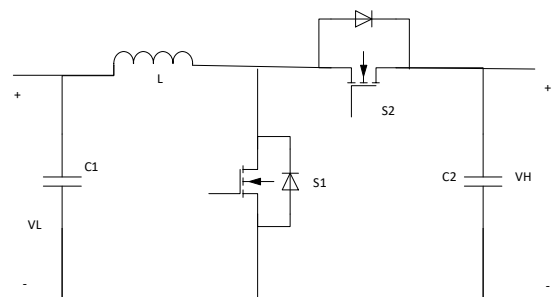

Gambar 7. Rangkaian bidirectional DC-DC converter

Bidirectional converter bekerja dalam 2 mode yaitu mode buck dan mode boost. Konverter akan bekerja pada mode buck ketika dilakukan pengisian baterai. Lalu mode boost digunakan ketika baterai sedang discharge atau mengisi beban.

\section{Sensor Tegangan}

Sensor tegangan adalah suatu alat yang mengukur tegangan pada alat elektronik. Sensor tegangan yang digunakan adalah rangkaian pembagi tegangan (voltage divider) seperti pada Gambar 8.

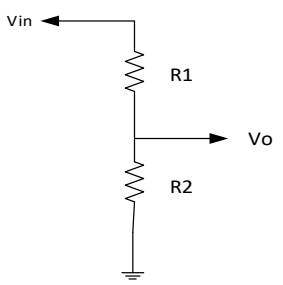

Gambar 8. Rangkaian pembagi tegangan

Tegangan pada baterai akan di konversikan ke dalam tegangan yang dapat di baca mikrokontroler yaitu nol sampai tiga koma tiga volt atau lima volt, menggunakan system ADC (Analog to Digital Convertion). Lalu tegangan tersebut diterjemahkan menjadi satuan digital melalui mikrokontroler agar dapat diatur lebih lanjut.

\section{E. Kontrol PI}

Kontrol Proportional-Integral (PI) digunakan untuk mengontrol tegangan output pada konverter DCDC yaitu dengan menyesuaikan sinyal kesalahan sebagai umpan balik loop kontrol.

Kontroler proporsional memiliki keluaran yang sebanding atau proporsional dengan besarnya sinyal kesalahan (selisih antara besaran yang diinginkan dengan harga aktualnya). Secara lebih sederhana dapat dikatakan bahwa keluaran kontroler proporsionalnya merupakan perkalian antara konstanta proporsional dengan masukanya.

Kontroler integral berfungsi menghasilkan respon sistem yang memiliki kesalahan keadaan yang bagus yaitu nol.

Kontroler PI dapat saling menutupi menutupi kekurangan dan kelebihan sehingga masing-masing dapat mempercepat reaksi sebuah sistem. Gambar 9 merupakan diagram blok dari kontrol PI.

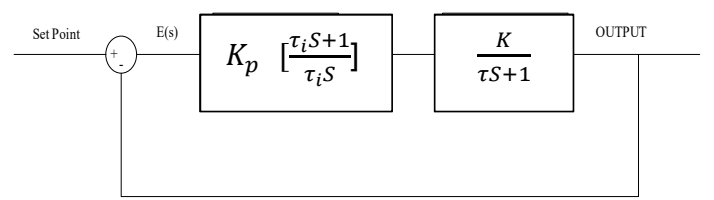

Gambar 9. Diagram blok sistem kontrol PI

Diagram blok sistem kontrol PI menggambarkan hubungan antara jumlah pengaturan, jumlah aktual dan output kontrol proporsional. Sinyal kesalahan (error) adalah perbedaan antara jumlah pengaturan dengan jumlah aktual.

\section{METODE PENELITIAN}

Pada penelitian ini terdapat perencanaan sistem yaitu pembuatan blok diagram sistem. Blok diagram sistem dapat dilihat pada Gambar 10.

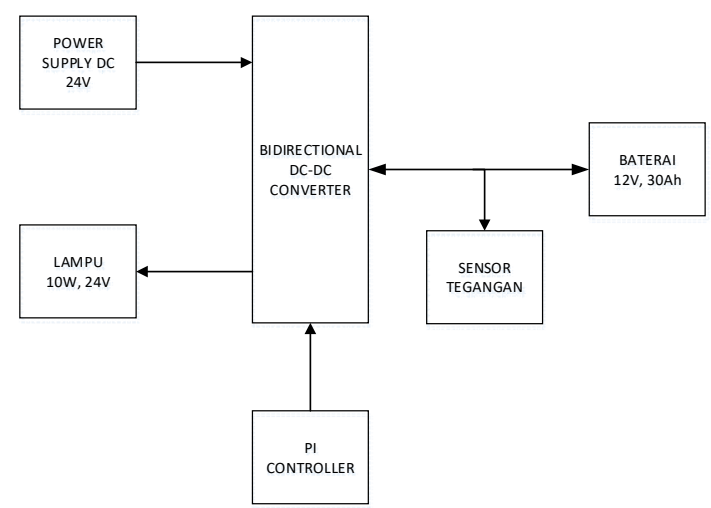

Gambar 10. Blok diagram sistem

Pada Gambar 10 dijelaskan bahwa power supply sebesar $24 \mathrm{~V}$ digunakan untuk mengisi baterai sebesar 12V. Tegangan yang dihasilkan power supply diturunkan menggunakan mode buck bidirectional agar sesuai dengan kebutuhan pengisian baterai. Ketika PLN padam maka baterai sebesar $12 \mathrm{~V}$ akan menyuplai beban sebsar $24 \mathrm{~V}$. Tegangan yang dihasilkan baterai 
Jurnal ECOTIPE, Vol. 7, No.2, Oktober 2020, Hal. 108-116

p-ISSN 2355-5068, e-ISSN 2622-4852

Akreditasi Kemenristekdikti (SINTA 4), SK. No.10/E/KPT/2019

DOI: 10.33019/jurnalecotipe.v7i2.1883

dinaikkan menggunakan mode boost bidirectional agar sesuai dengan kebutuhan beban. Proses switching dari bidirectional DC-DC converter dilakukan dengan mengatur PWM (Pulse Width Modulation) agar didapatkan tegangan yang maksimal.

\section{A. Pengujian Mode Buck}

Pada pengujian buck converter yang dilakukan pada software PSIM rangkaian buck converter terdiri dari tegangan masukan $\left(V_{S}\right)$ sebesar $24 \mathrm{~V}$, kapasitor $(C)$ sebesar $133,93 \mu F$, tegangan keluaran $\left(V_{o}\right)$ sebesar $14 \mathrm{~V}$. Dengan tegangan masukan sebesar $24 \mathrm{~V}$ dan diatur duty cycle $10 \%$ hingga $60 \%$. Secara teoritis, keluaran konverter akan sebanding dengan duty cycle PWM yang digunakan untuk menyulut mosfet seperti pada gambar 11.

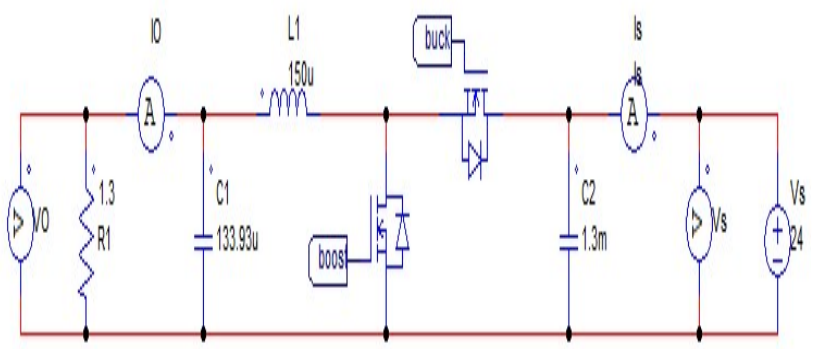

Gambar 10. Rangkaian simulasi mode buck

Hasil dari perubahan duty cycle tehadap perubahan tegangan yang disajikan dalam bentuk tabel 1.

Tabel 1. Hasil simulasi mode buck

\begin{tabular}{|c|c|c|c|c|c|c|}
\hline $\begin{array}{c}\text { Duty } \\
(\%)\end{array}$ & $\begin{array}{c}\text { Vin } \\
(\mathrm{V})\end{array}$ & $\begin{array}{c}\text { Iin } \\
(\mathrm{A})\end{array}$ & $\begin{array}{c}\text { Vo } \\
(\mathrm{V})\end{array}$ & Io (A) & $\begin{array}{c}\text { Vo } \\
\text { teori } \\
(\mathrm{V})\end{array}$ & $\begin{array}{c}\text { Error } \\
(\%)\end{array}$ \\
\hline 10 & 24 & 1,78 & 2,4 & 1,84 & 2,4 & 0 \\
\hline 20 & 24 & 3,57 & 4,79 & 3,69 & 4,8 & 0,208 \\
\hline 30 & 24 & 5,38 & 7,19 & 5,54 & 7,2 & 0,139 \\
\hline 40 & 24 & 7,21 & 9,6 & 7,38 & 9,6 & 0 \\
\hline 50 & 24 & 9,04 & 12 & 9,23 & 12 & 0 \\
\hline 58 & 24 & 10,53 & 13,92 & 10,71 & 13,92 & 0 \\
\hline 60 & 24 & 10,9 & 14,4 & 11,08 & 14,4 & 0 \\
\hline
\end{tabular}

Pada Tabel 1 digunakan duty cycle sebesar 58\% guna mendapatkan tegangan 14 Volt untuk mencharging sebuah baterai. Dari pengujian diatas dapat dilihat bahwa buck converter mampu menurunkan tegangan hingga $2,4 \mathrm{Volt}$ dengan duty cycle $10 \%$.

\section{B. Pengujian Mode Boost}

Pada pengujian boost converter rangkaiannya terdiri dari tegangan masukan $\left(V_{s}\right)$ sebesar $12 \mathrm{~V}$, kapasitor $(C)$ sebesar $1,3 \mathrm{mF}$, induktor $(L)$ sebesar 150 $\mu H$, dan tegangan keluaran $\left(V_{o}\right)$ sebesar $24 \mathrm{~V}$. Dengan tegangan masukan sebesar $12 \mathrm{~V}$ dan diatur duty cycle $10 \%$ hingga $60 \%$. Secara teoritis, keluaran konverter akan sebanding dengan duty cycle PWM yang digunakan untuk menyulut mosfet seperti pada gambar 12.

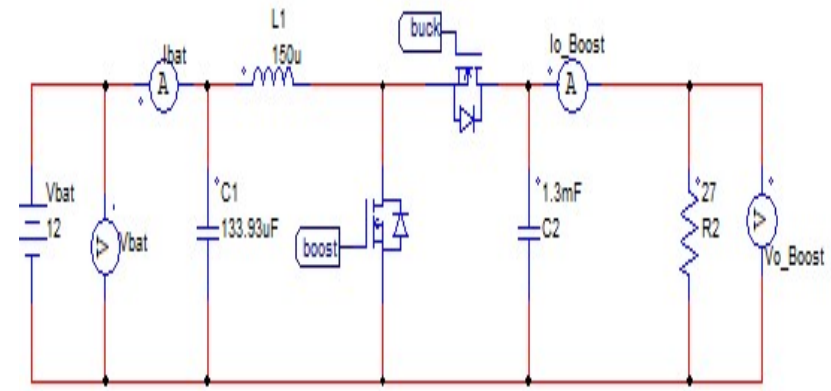

Gambar 11. Rangkaian simulasi mode boost

Hasil dari perubahan duty cycle tehadap perubahan tegangan yang disajikan dalam bentuk tabel 2.

Tabel 2. Hasil simulasi mode boost

\begin{tabular}{|c|c|c|c|c|c|c|}
\hline $\begin{array}{c}\text { Duty } \\
(\%)\end{array}$ & $\begin{array}{c}\text { Vin } \\
(\mathrm{V})\end{array}$ & $\begin{array}{c}\text { Iin } \\
(\mathrm{A})\end{array}$ & $\begin{array}{c}\text { Vo } \\
(\mathrm{V})\end{array}$ & Io (A) & $\begin{array}{c}\text { Vo } \\
\text { teori } \\
(\mathrm{V})\end{array}$ & $\begin{array}{c}\text { Error } \\
(\%)\end{array}$ \\
\hline 10 & 12 & 0,21 & 13,33 & 0,44 & 13,33 & 0 \\
\hline 20 & 12 & 0,05 & 15 & 0,5 & 15 & 0 \\
\hline 30 & 12 & 0,03 & 17,37 & 0,58 & 17,14 & 1,34 \\
\hline 40 & 12 & 0,013 & 20,22 & 0,67 & 20 & 1,1 \\
\hline 50 & 12 & 0,16 & 24,01 & 0,8 & 24 & 0,04 \\
\hline 60 & 12 & 0,77 & 30,03 & 1 & 30 & 0,1 \\
\hline
\end{tabular}

Pada Tabel 2, digunakan duty cycle sebesar 50\% guna mendapatkan tegangan 24 Volt untuk menyuplai beban. Dari pengujian diatas dapat dilihat bahwa boost converter mampu menaikkan tegangan hingga 30,03 Volt dengan duty cycle $60 \%$.

\section{Perhitungan Kontrol Proportional Integral dengan metode analitik}


Jurnal ECOTIPE, Vol. 7, No.2, Oktober 2020, Hal. 108-116

p-ISSN 2355-5068, e-ISSN 2622-4852

Akreditasi Kemenristekdikti (SINTA 4), SK. No.10/E/KPT/2019

DOI: 10.33019/jurnalecotipe.v7i2.1883

Seluruh nilai komponen yang terdapat pada rangkaian simulasi, diperoleh dari perhitungan desain rangkaian bidirectional converter dengan nilai duty cycle yang sesuai dengan perhitungan. Dari simulasi yang dibuat menghasilkan nilai tegangan output yang hampir mendekati nilai setpoint yang diinginkan. Dari hasil running tersebut diperoleh gelombang respon yang nantinya akan dibuat sebagai acuan untuk perhitungan kontrol PI melalui nilai time settling dan output respon dari gelombang respon simulasi.

Perhitungan kontrol PI dengan metode analitik pada mode buck:

Waktu steady state $\left(\boldsymbol{T}_{\boldsymbol{s}}\right)=0,0025 \mathrm{~s}$

Tegangan steady state $\left(\boldsymbol{Y}_{\boldsymbol{s s}}\right)=13,92 \mathrm{~V}$

Tegangan masukan $\left(X_{S S}\right)=24 \mathrm{~V}$

Mencari Open Loop Transfer Fuction

Gain Over All (K)

$$
\begin{aligned}
K & =\frac{Y_{S S}}{X_{S S}} \\
& =\frac{13,92}{24} \\
& =0,58
\end{aligned}
$$

Time Konstan $(\tau)$ :

$$
\begin{array}{ll}
t_{s} \quad=5 \tau \\
0,0025 \mathrm{~s} & =5 \tau \\
\tau & =0,0005 \mathrm{~s}
\end{array}
$$

Sehinggga dapat ditentukan open loop transfer function adalah sebagai berikut :

$$
\begin{aligned}
& \text { OLTF }=\frac{\mathrm{K}}{\tau \mathrm{S}+1} \\
& \text { OLTF }=\frac{0,58}{0,0005 \mathrm{~S}+1}
\end{aligned}
$$

Untuk Close Loop Transfer function (CLTF) sebagai berikut :

$t_{s} *=5 \tau$

$t_{s} *=\frac{1}{n^{*}} x t s$

$t_{s} *=\frac{1}{5} x 0,0025 s$

$t_{s} *=0,0005 s$

Maka $\tau^{*}=\frac{0,0005}{5}=0,0001 s$

Sehingga :

CLTF $=\frac{1}{\tau^{*} s+1}$

$$
\begin{aligned}
& =\frac{1}{0,0001 s+1} \\
K_{p} & =\frac{\tau}{\mathrm{k} \tau^{*}} \\
& =\frac{0,0005}{0,58 \times 0,0001} \\
& =8,62 \\
& =\frac{K_{p}}{\tau} \\
K_{i} & =\frac{8,62}{0,0005} \\
& =17240
\end{aligned}
$$

Perhitungan kontrol PI dengan metode analitik pada mode boost :

Waktu steady state $\left(\boldsymbol{T}_{\boldsymbol{s}}\right)=0,0354 \mathrm{~s}$

Tegangan steady state $\left(\boldsymbol{Y}_{\boldsymbol{s s}}\right)=23,84 \mathrm{~V}$

Tegangan masukan $\left(X_{S S}\right)=12 \mathrm{~V}$

Mencari Open Loop Transfer Fuction

Gain Over All (K)

$$
\begin{aligned}
K & =\frac{Y_{S S}}{X_{S S}} \\
& =\frac{23,84}{12} \\
& =1,99
\end{aligned}
$$

Time Konstan $(\tau)$ :

$$
\begin{aligned}
& t_{s}=5 \tau \\
& 0,03545 \mathrm{~s}=5 \tau \\
& \tau \quad=0,00708 \mathrm{~s}
\end{aligned}
$$

Sehinggga dapat ditentukan open loop transfer function adalah sebagai berikut :

$$
\begin{aligned}
& \text { OLTF }=\frac{\mathrm{K}}{\tau \mathrm{S}+1} \\
& \text { OLTF }=\frac{1,99}{0,00708 \mathrm{~S}+1}
\end{aligned}
$$

Untuk Close Loop Transfer function (CLTF) sebagai berikut :

$$
\begin{aligned}
& t_{s} *=5 \tau \\
& t_{s} *=\frac{1}{n^{*}} \times t s \\
& t_{s} *=\frac{1}{5} \times 0,0354 \mathrm{~s}
\end{aligned}
$$


Jurnal ECOTIPE, Vol. 7, No.2, Oktober 2020, Hal. 108-116

p-ISSN 2355-5068, e-ISSN 2622-4852

Akreditasi Kemenristekdikti (SINTA 4), SK. No.10/E/KPT/2019

DOI: 10.33019/jurnalecotipe.v7i2.1883

$t_{s} *=0,00708 s$

Maka $\tau^{*}=\frac{0,00708}{5}=0,001416 s$

Sehingga :

$$
\begin{aligned}
\text { CLTF } & =\frac{1}{\tau^{*} s+1} \\
& =\frac{1}{0,001416 s+1} \\
K_{p} & =\frac{\tau}{\mathrm{k \tau} \tau^{*}} \\
& =\frac{0,00708}{1,99 \times 0,001416} \\
& =2,44 \\
& =\frac{K_{p}}{\tau} \\
K_{i} & =\frac{2,44}{0,00708} \\
& =344,63
\end{aligned}
$$

\section{HASIL PENELITIAN DAN PEMBAHASAN}

Pada bidirectional converter menggunakan software PSIM untuk simulasi yang dikontrol menggunakan kontrol PI.

\section{A. Pengujian Charging Baterai}

Pada Gambar 12 yaitu mode buck digunakan untuk mengetahui tegangan keluaran konverter yang telah dikontrol menggunakan kontrol PI sehingga didapatkan tegangan keluaran konstan sebesar $14 \mathrm{~V}$ sesuai dengan tegangan pengisian pada baterai. Rangkaian simulasi mode buck untuk charging baterai dapat dilihat pada Gambar 12.
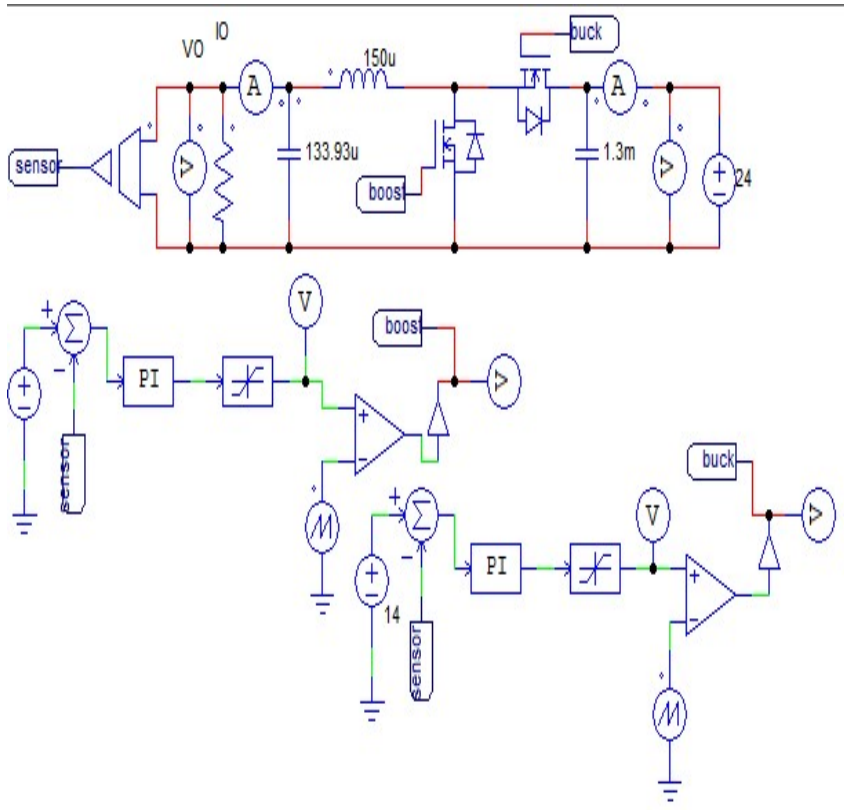

Gambar 12. Rangkaian simulasi mode buck untuk charging baterai

Pada gambar 12 merupakan rangkaian mode buck dengan kontrol PI untuk charging baterai. Dari simulasi tersebut dapat dibandingkan bentuk respon ketika sebelum diberi kontrol PI dan sesudah diberi kontrol PI.

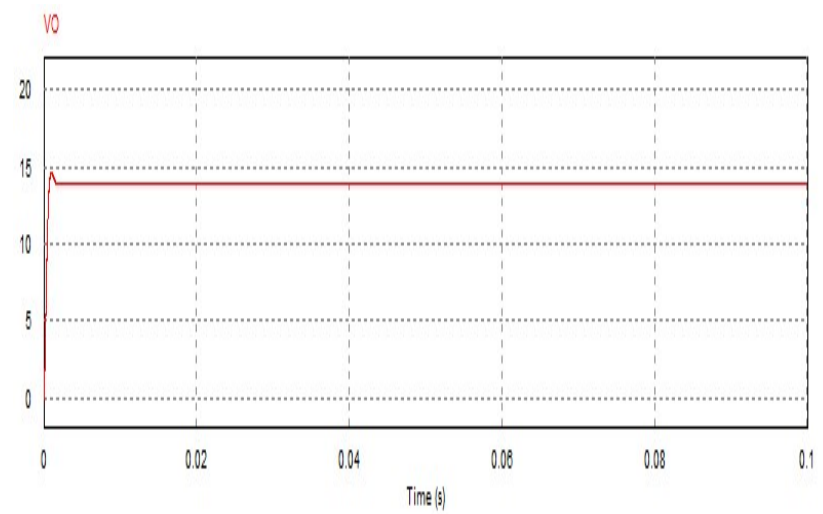

Gambar 13. Respon sistem mode buck tanpa kontrol dengan duty cycle $58 \%$

Gambar 13 menunjukkan hasil respon sistem tanpa kontrol dengan duty cycle sesuai dengan desain perhitungan mode buck konverter yaitu sebesar 58\%. Tegangan keluaran yang didapatkan sebesar 13,92V. Sistem tersebut mulai mencapai titik steady state pada saat 0,0025 s tetapi masih ada overshoot. 
Jurnal ECOTIPE, Vol. 7, No.2, Oktober 2020, Hal. 108-116

p-ISSN 2355-5068, e-ISSN 2622-4852

Akreditasi Kemenristekdikti (SINTA 4), SK. No.10/E/KPT/2019

DOI: 10.33019/jurnalecotipe.v7i2.1883

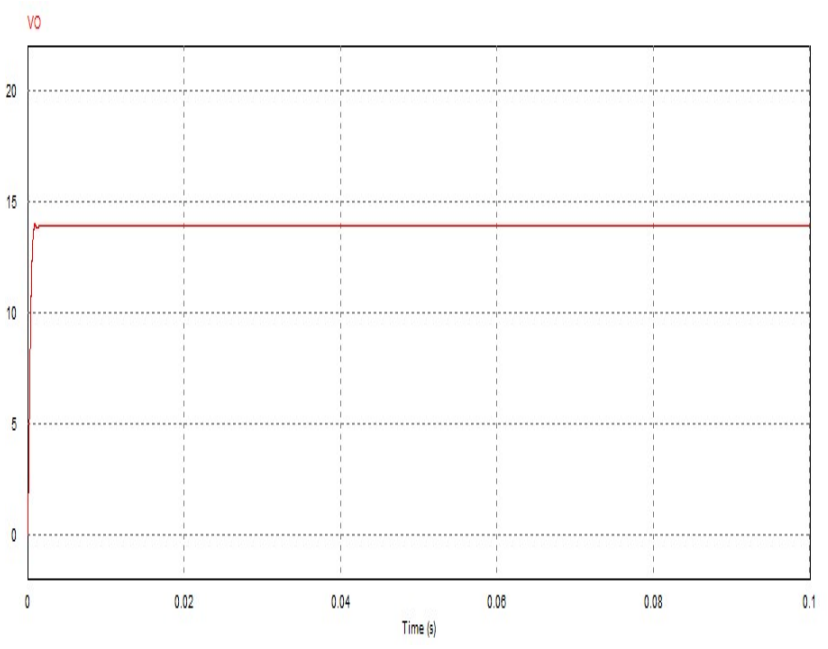

Gambar 14. Respon sistem mode buck dengan kontrol PI

Gambar 14 menunjukkan hasil respon sistem dengan kontrol PI metode analitik. Nilai $K_{p}$ yang digunakan berkisar 8,62, dan nilai $K_{i}$ sebesar 17240 dengan setpoint yang diinginkan berupa tegangan sebesar $14 \mathrm{~V}$. Dengan menggunakan kontrol PI didapatkan tegangan keluaran yang dijaga konstan sebesar 13,99V.dan mencapai titik steady state lebih cepat yaitu saat $0,001 \mathrm{~s}$.

\section{B. Pengujian Baterai Untuk Suplai Beban}

Pada Gambar 15 yaitu mode boost digunakan untuk mengetahui tegangan keluaran konverter yang telah dikontrol menggunakan kontrol PI sehingga didapatkan tegangan keluaran konstan sebesar $24 \mathrm{~V}$ untuk suplai beban.

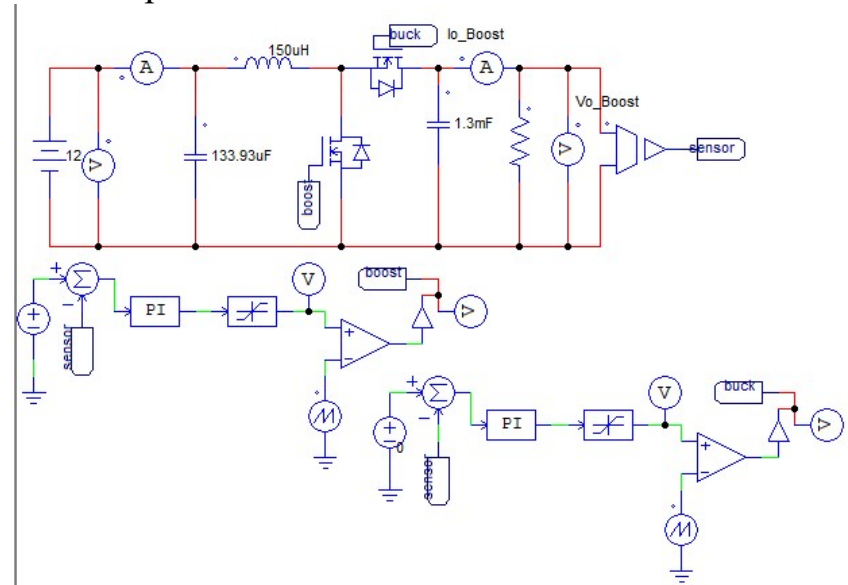

Gambar 15. Rangkaian simulasi mode boost untuk discharging baterai
Pada Gambar 15 merupakan rangkaian mode boost dengan kontrol PI i untuk discharging baterai yaitu kondisi saat beban di supply oleh baterai. Dari simulasi tersebut dapat dibandingkan bentuk respon ketika sebelum diberi kontrol PI dan sesudah diberi kontrol PI.

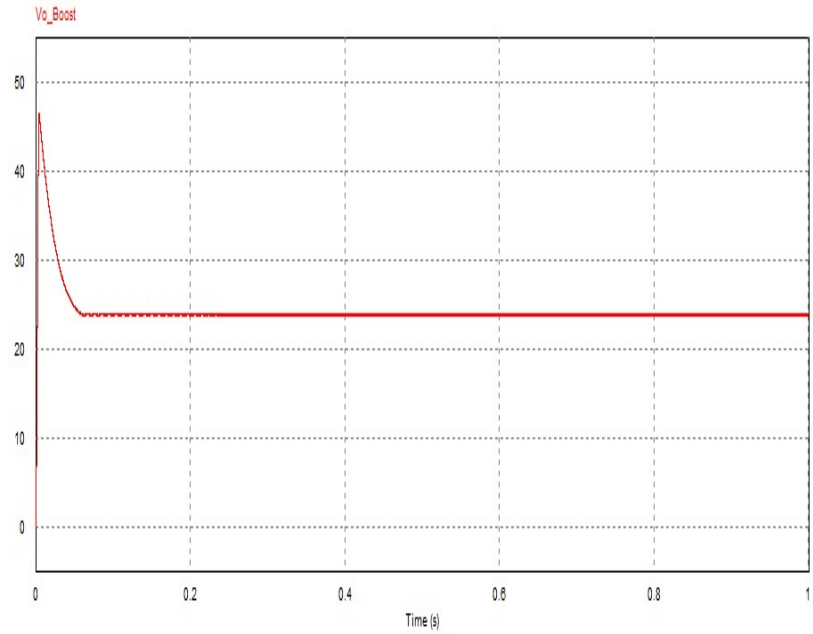

Gambar 16. Respon sistem mode boost tanpa kontrol dengan duty cycle 50\%

Gambar 16 menunjukkan hasil respon sistem tanpa kontrol dengan duty cycle sesuai desain perhitungan mode boost konverter yaitu sebesar $50 \%$. Tetapi tegangan keluaran yang dihasilkan sebesar $23,84 \mathrm{~V}$. Sistem tersebut mulai mencapai titik steady state pada saat $0,035 \mathrm{~s}$.

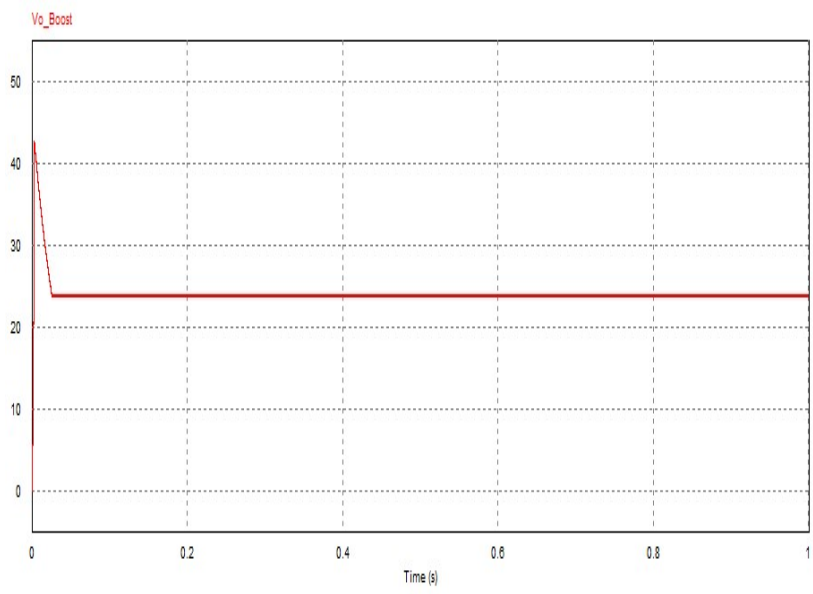

Gambar 17. Respon sistem mode boost dengan kontrol PI 
Jurnal ECOTIPE, Vol. 7, No.2, Oktober 2020, Hal. 108-116

p-ISSN 2355-5068, e-ISSN 2622-4852

Akreditasi Kemenristekdikti (SINTA 4), SK. No.10/E/KPT/2019

DOI: 10.33019/jurnalecotipe.v7i2.1883

Gambar 17 menunjukkan hasil respon sistem dengan menggunakan kontrol PI metode analitik. Nilai $K_{p}$ yang digunakan berkisar 2,44, dan nilai $K_{i}$ sebesar 344,63 dengan setpoint yang diinginkan berupa tegangan sebesar 24V. Dengan menggunakan kontrol PI didapatkan tegangan keluaran yang dijaga konstan sebesar 23,99V.dan mencapai titik steady state lebih cepat yaitu saat $0,01 \mathrm{~s}$.

\section{KESIMPULAN}

Hasil dari berbagai tahapan proses yang telah dilakukan dalam mengerjakan simulasi bidirectional $D C-D C$ converter dapat diamati bahwa saat konverter belum menggunakan kontrol PI pada mode buck dengan duty cycle sebesar 58\% didapatkan tegangan keluaran sebesar 13,92V dan mode boost dengan duty cycle sebesar $50 \%$ didapatkan tegangan keluaran sebesar 23,84V. Setelah menggunakan kontrol PI metode analitik, proses charging pada mode buck dengan nilai $K_{p}$ sebesar 8,62 dan $K_{i}$ sebesar 17240 didapatkan nilai tegangan keluaran sebesar $13,99 \mathrm{~V}$ dari setpoint yang diinginkan yaitu $14 \mathrm{~V}$ dan saat proses discharging pada mode boost dengan nilai $K_{p}$ sebesar 2,44 dan $K_{i}$ sebesar 344,63 didapatkan nilai tegangan keluaran sebesar 23,99V dari setpoint yang diinginkan yaitu $24 \mathrm{~V}$.

\section{REFERENSI}

[1] Hart, Daniel W.2011. "Power Electronics". The McGraw-Hill Companies. New York,Amerika.

[2] Elnady, A. "PI Controller Based Operational Scheme to Stabilize Voltage in Microgrid." 2019 Advances in Science and Engineering Technology International Conferences (ASET). IEEE, 2019.

[3] Halder, T. "PI controller tuning \& stability analysis of the flyback SMPS." 2014 IEEE 6th India International Conference on Power Electronics (IICPE). IEEE, 2014.

[4] Rabiaa, Ounis, et al. "Cascade control loop of dcdc boost converter using pi controller." 2018 International Symposium on Advanced Electrical and Communication Technologies (ISAECT). IEEE, 2018.
[5] Chao, Kuei-Hsiang, et al. "Design and implementation of a bidirectional DC-DC converter for stand-alone photovoltaic systems." energy 4 (2013): 8.

[6] Raharja, Lucky Pradigta Setiya, et al. "Perancangan Dan Implementasi $D C-D C$ Bidirectional Converter Dengan Sumber Energi Listrik Dari Panel Surya Dan Baterai Untuk Pemenuhan Kebutuhan Daya Listrik Beban”.Jurnal Teknologi Terpadu Vol. 7 No. 2.

[7] Ravi, Deepak, et al. "Bidirectional DC to DC converters: an overview of various topologies, switching schemes and control techniques." International Journal of Engineering \& Technology 7.4 .5 (2018): 360-365.

[8] Sudiharto, Indhana, and Indra Ferdiansyah. "Diah Septi Yanaratri Mochamad Abdul Mughis,"." Design and Implementation of Partial M-Type Zero Voltage Resonant Circuit Interleaved Bidirectional DC-DC Converter (Energy Storage and Load Sharing)," in 2018 International Electronics Symposium on Engineering Technology and Applications (IESETA), Bali, Indonesia. 2018.

[9] Shahin, M. "Analysis of bidirectional SEPIC/Zeta converter with coupled inductor." 2015 International Conference on Technological Advancements in Power and Energy (TAP Energy). IEEE, 2015.

[10] Eviningsih, Rachma Prilian, et al. "Controlled bidirectional converter using PID for charging battery in the stand-alone wind turbine system with modified P\&O to obtain MPPT." 2017 International Conference on Green Energy and Applications (ICGEA). IEEE, 2017. 